Cad.Est.Ling., Campinas, (44):239-250, Jan./Jun. 2003

\title{
COESÃO E INTERATIVIDADE EM TEXTO DE ELOCUÇÃO FORMAL *
}

\author{
HELENA HATHSUE NAGAMINE BRANDÃO \\ (USP)
}

\begin{abstract}
In this essay I intend to verify how a genre of textual formal elocution - the conference - is organized, from both a linguistic construction point of view as well as its pragmatic and interactive marks. I will analyze the presence of identifying elements not only related to the oral language but also the ones derived from the written language, since the conference is a genre of oral form, used in formal and academic settings. I will start by explaining the theoretical framework in which the analysis is conducted.
\end{abstract}

Neste trabalho pretendo verificar como se organiza um gênero textual de elocução formal - a conferência - tanto do ponto de vista de sua construção lingüística e textual quanto em relação às suas marcas pragmáticas e interacionais; para isso vou analisar a presença de elementos caracterizadores não só da sua oralidade como daqueles próprios da modalidade escrita, uma vez que se trata de um gênero de modalidade oral, proferido em situação formal, acadêmica. Exponho, inicialmente, o quadro teórico em que a análise se insere.

\section{CONSIDERAÇÕES TEÓRICAS}

Os estudos iniciais sobre oralidade e escrita pautaram-se por destacar as diferenças entre as duas modalidades numa perspectiva dicotômica, opondo, de forma um tanto esquemática, língua falada e língua escrita cujas características eram representadas num paradigma do tipo: contextualizada $\mathrm{x}$ descontextualizada, redundante $\mathrm{x}$ condensada, não planejada $\mathrm{x}$ planejada, imprecisa $\mathrm{x}$ precisa, não normatizada x normatizada, fragmentária x completa. Nesse sentido, é clássico o trabalho de Chafe (1985) que, a partir de critérios utilizados por Ochs (1979) para identificar escrita planejada e fala não planejada, apresenta um estudo pioneiro ao comparar conversação espontânea e prosa acadêmica, consideradas por ele dois gêneros prototípicos da fala e da escrita. Chafe sugere que a língua escrita caracteriza-se por um alto grau de integração acarretada pela lentidão da escrita e tem como efeito a

\footnotetext{
* Versão ligeiramente modificada de texto publicado em Actas II - VIII Simposio Internacional de Comunicación Social, Santiago de Cuba, 20-24 de janeiro de 2003.
} 
velocidade da leitura, enquanto a língua falada apresenta uma característica fragmentada, resultante em parte da espontaneidade natural da fala que provavelmente reflete a natureza convulsiva do pensamento que se processa concomitantemente à fala. Por outro lado, a língua falada caracteriza-se por um alto grau de envolvimento em contraste com o distanciamento da língua escrita. Eis o que diz Chafe:

\begin{abstract}
Num trabalho anterior (Chafe, 1982), discuti duas grandes dimensões que distinguem a língua escrita da língua falada, no que diz respeito às propriedades lingüísticas destas duas modalidades. Sugeri que estas dimensões são determinadas por duas diferenças básicas nos processos de escrever e de falar. $\mathrm{O}$ fato de a escrita ser um processo lento, deliberado e editável, ao passo que a fala se realiza no momento, leva à diferença que denominei de qualidade de integração da escrita em oposição à qualidade de fragmentação da fala. $\mathrm{O}$ fato de a escrita ser uma atividade solitária, ao passo que a fala ocorre caracteristicamente num ambiente de interação social, faz com que a língua escrita tenha uma qualidade de distanciamento que contrasta com o envolvimento da língua falada (Chafe, 1985:1)
\end{abstract}

Portanto, na perspectiva de Chafe, fala e escrita se opõem, fundamentalmente pelas dicotomias integração x fragmentação e distanciamento x envolvimento, características advindas das condições de produção de cada uma delas: o modo de produção no tempo e a forma de interação estabelecida entre os interlocutores. Assim:

- a escrita, por ser produzida a distância, sem que os interlocutores interajam face a face, caracteriza-se por um afastamento ou menor envolvimento do escrevente com seu parceiro de interlocução (às vezes, o leitor imaginário) e maior envolvimento com o texto ou o assunto. E, por dispor de maior tempo para sua elaboração, como, por exemplo, para o planejamento, do texto a ser enunciado, a escrita caracteriza-se ainda pela sua integração;

- a modalidade falada, pela própria condição de ser uma interação face a face, caracteriza-se:

- pelo envolvimento dos interlocutores consigo mesmo e com o outro;

- por um planejamento local, que se dá no momento mesmo do ato enunciativo;

- e, consequentemente, pela fragmentação acrescida do fato de que outras linguagens que não apenas a verbal atuam intersemioticamente, possibilitando uma comunicação mais rápida.

Atualmente, entretanto, os lingüistas defendem outro paradigma partindo da hipótese de que as diferenças entre fala e escrita se dão dentro de um continuum tipológico das práticas sociais de produção textual e não numa relação dicotômica de fala e escrita situadas em pólos opostos.

Não resta dúvida de que existem textos tipicamente orais e outros que são tipicamente escritos. Também é verdade que há certos fenômenos que são mediados pela escrita e outros que são mediados pela fala. As práticas sociais criam formas de transmissão do conhecimento apropriadas tanto à cultura como aos modos de produção. Estas duas classes de textos exibirão diferenças sensíveis entre si, mas os textos restantes estarão dentro da faixa de um contínuo. É até provável que não sejam muitas as diferenças essencialmente lingüísticas e que a maioria 
delas seja de processamento, em função do tempo, das condições e dos meios de produção,

além das diferenças do tipo de texto realizado. (Marcuschi,1993:71)

Essa orientação situa-se numa perspectiva sócio-interacionista em que os processos de produção do sentido são sensíveis aos fatos culturais e são marcados por atividades de negociação que envolvem falante/ouvinte e escritor/leitor. Fala e escrita, enquanto práticas sociais, são práticas discursivas que se produzem ligadas a instituições. A comunidade de falantes tem, de certa forma, codificadas suas formas de interação, isto é, cada situação específica de interação exige um certo gênero de texto; essas formas codificadas, tipos "relativamente estáveis" a que Bakhtin(1992) chama de gêneros do discurso, sejam orais sejam escritas, são construídas socialmente de acordo com as diferentes esferas da atividade humana.

Neste trabalho, parto do pressuposto teórico de que entre língua oral e língua escrita não existe uma fronteira nitidamente delimitadora que as coloque em campos dicotômicos, mas que entre um gênero tipicamente falado, como a conversação espontânea, e um gênero tipicamente escrito, como o ensaio acadêmico, existe um continuum de gêneros variados que carregam características predominantes ou combinadas ora de uma modalidade ora de outra. Nesse sentido, a conferência é um gênero que, por ser proferido em determinadas condições e, sobretudo em situação formal mais complexa, traz características do escrito (o planejamento prévio) e também características do falado por ser proferido diante de um público em presença.

\section{A CONFERÊNCIA: DINÂMICA FALA E ESCRITA}

Vou analisar parte de uma conferência proferida em situação acadêmica formal em que o locutor, uma mulher, professora universitária, discorre sobre o tema "Estética no Brasil na década de 30". Este texto faz parte do corpus do Projeto Norma Urbana Culta - São Paulo (NURC - SP) ${ }^{1}$.

Pelo caráter monologal da conferência e pela assimetria interacional, vou analisar como o locutor propõe, desenvolve o tema e interage com o auditório presente, abordando aspectos da sua estrutura composicional e o estilo na dinamicidade estabelecida pelo jogo entre oralidade e escrita.

\section{O tópico como elemento de coesão e de estruturação discursiva}

Considerando a conferência acadêmica como um gênero misto, isto é, um gênero que reúne ao mesmo tempo as propriedades do texto falado e do texto escrito, vou

${ }^{1}$ O NURC-SP insere-se num projeto mais amplo (Projeto NURC - BR) com o objetivo de traçar um mapa caracterizador da modalidade oral dos falantes cultos do português brasileiro; para isso foi constituído um corpus com material coletado, concomitantemente, em outras grandes capitais brasileiras: Rio de Janeiro (RJ), Salvador (BA), Recife (PE) e Porto Alegre (RS). Esse corpus abrange três tipos de discurso: elocuções formais (Efs) que compreendem aulas e conferências, diálogos entre dois informantes (D2s) e diálogos entre informante e documentador (DID). 
caracterizá-lo como um gênero falado de estilo escrito. Em outras palavras, por ser um texto falado mas de caráter acadêmico-científico, isto é, uma modalidade de elocução formal, e monogerado, a conferência apresenta uma característica fundamental da língua escrita: o planejamento prévio. O simples fato de, para que uma conferência aconteça, uma série de condições tenham que ser acertadas previamente, como o local e a hora de realização, o tema e o público visado, já se tem o quadro enunciativo em que se deve inserir esse gênero discursivo. Nesse quadro, vamos destacar para análise as estratégias de desenvolvimento temático e, nesse sentido, o tópico ocupa um lugar essencial.

Para os analistas da conversação (Marcuschi,1988; Jubran et alii, 1996), as interações verbais, dialogadas ou não, têm uma estrutura possível de ser identificada com base na sua organização tópica, definindo-se tópico como aquilo sobre o qual se está falando, ou ainda, aquilo que é tomado pelos interlocutores como o assunto ou o tema da conversação. Como a conversação se realiza como uma seqüenciação de tópicos discursivos, o tópico se torna o elemento estruturador da organização discursiva, constituindo-se em fator central no tratamento da coesão e coerência conversacional.

O tópico se define por duas propriedades:

1) a centração - o falar acerca de alguma coisa de maneira que haja uma relação de interdependência semântica entre os enunciados, utilizando-se de referentes explícitos ou inferíveis;

2) organicidade - manifesta por relações de interdependência que se estabelecem simultaneamente em dois planos:

a) no plano hierárquico ou vertical, a organicidade se estabelece conforme as dependências de super-ordenação e sub-ordenação entre tópicos que se implicam pelo grau de abrangência do assunto. Essas relações de interdependência entre os níveis hierárquicos da organização tópica podem ser representadas no que se tem chamado de Quadro Tópico que, determinado pelo nível de hierarquia selecionado pelo analista, constitui-se em elemento operatório na descrição de um corpus.

b) no plano sequencial ou horizontal, em que temos as articulações intertópicas em termos de adjacências ou interposições na linha discursiva. Aqui, dois processos básicos indicam o desenvolvimento progressão do assunto:

i) a continuidade que decorre de uma organização sequencial dos segmentos tópicos de forma que a passagem de um tópico para outro se dá por contiguidade, após o esgotamento do assunto em relevo;

ii) a descontinuidade que decorre de uma perturbação da seqüencialidade linear em que um tópico é introduzido na linha discursiva antes de se ter esgotado o precedente, podendo ou não haver o retorno deste após a interrupção; se acontecer o retorno tem-se um caso de inserção, se não, tem-se ruptura ou corte.

O reconhecimento dessas propriedades indica a possibilidade de descrição de procedimentos de estruturação tópica, uma vez que aquilo de que se fala não pode ser 
desvinculado do como se fala. Assim, a topicalidade não é uma questão apenas de conteúdo, mas um princípio organizador do discurso, que apresenta, portanto, no plano de sua realização, uma estrutura passível de ser identificada e analisada.

\section{A ORGANIZAÇÃO TÓPICA DO TEXTO EM ANÁLISE.}

A conferencista é crítica de arte e, na época da conferência, era professora de Estética da Pintura na Faculdade de Filosofia, Letras e Ciências Sociais da USP. A conferência em análise foi proferida em 21/2/73 e o tema era "Estética no Brasil, na década de 30". Na década de 30, mais exatamente em 1934, foi criada a Faculdade de Filosofia, Letras e Ciências Sociais, embrião da Universidade de São Paulo. Criada a Faculdade, foram convidados professores franceses para dar aula nessa faculdade; para cá vieram, então, jovens professores que depois se tornaram famosos, dentre eles, Claude Lévi Strauss e Roger Bastide, referidos na conferência. A conferencista é a profa. Gilda de Mello e Sousa que foi aluna desses professores nos finais da década de trinta.

O texto em análise está transcrito em Castilho \& Preti (1986:72-89), e corresponde a 43 minutos de duração, compreendendo a Introdução e a primeira parte do Desenvolvimento; há uma segunda parte no desenvolvimento que não será objeto de nossa análise. Analisaremos, portanto, a introdução e a primeira parte do desenvolvimento.

Pelo caráter bastante coesivo presente na temática desenvolvida, podemos dizer que, pelo critério da organicidade, o supertópico (ST) é "A estética no Brasil na década de 30". Este ST se desdobra em três grandes tópicos:

Tópico 1: abordagem do tema da conferência (que corresponde à Introdução e vai da linha 1 à metade da 33);

Tópico 2: manifestações estéticas no decênio de 30 (que corresponde à primeira parte do desenvolvimento e vai da metade da linha 33 até 753);

Tópico 3: a estética de Mário de Andrade (parte não analisada neste trabalho)

Tópico 4: conclusão (idem).

\subsection{A introdução: organização tópica}

A introdução tem por finalidade negociar com o auditório o tema, pois numa perspectiva intersdiscursiva, a conferencista procura situar sua fala em relação a outras palestras já proferidas no ciclo de palestras que estava acontecendo e procurando não ser repetitiva, vai propor uma fuga ao tema e um tratamento mais pessoal do assunto. Assim, dentro deste T temos:

Subtópico 1: abordagem do tema

1 [...] ahn:: o tema que me éh me foi dado é da estética na década de TRINTA...eu vou desde o início... 


\section{declarar que eu vou fugir um pouco ao meu tema...}

e talvez no decorrer da palestra fique esclarecido...

fique esclarecida a minha opção...éh:: em todo

caso aviso já desde o início

Subtópico 2: justificativa 1- muitas das ricas manifestações artísticas desse decênio já devem ter sido tratadas:

[...] porque éh:: escolhi

essa orientação... a década de trinta é uma década

muito rica de manifestações estéticas mas muitas

das manifestações que poderiam me interessar aqui já

10 foram... eu creio...tratados por out/tratadas

a por outras pessoas não irão ser tratadas... porque

estética abran::ge:: enfim a :: arquitetura:: as artes

plásticas em geral a arquitetura e pintura... e::

e pode eventualmente entrar pelo campo da literatura

Subtópico 3: justificativa 2: é mais importante parar nas meditações de Mário de Andrade sobre o sistema de Arte do que falar das pequenas manifestações esporádicas que não tiveram importância posterior:

$15[\ldots]$ por outro lado porque neste momento

ah:: está ah:: ah... trabalhando um esteta que talvez

seja o maior esteta que o Brasil já teve que é

Mário de Andrade... e eu acredito que é mais

importante para nós pararmos um pouco na

20 meditação do sistema da ARte que ele estabeleceu... do que em pequenas manifestações espoRÁ::dicas... que não terão tanta importância posterior...

Subtópico 4: propostas de desenvolvimento do tema: a) falar de algumas manifestações estéticas no período e b) fixar-se no pensamento de Mário de Andrade:

$[\ldots]$ de

modo que eu vou tentar na primeira parte da

minha palestra me referir... a algumas

25 manifestações... e depois me fixar... na::na no pensamento estético de Mário... mesmo aqui eu fiz uma pê/ uma:: uma::ah o meu enfoque é muito pessoal porque éh:: tendo que escolher alguns pensadores eu preferi escolher aqueles que estão

30 ligados à Faculdade de Filosofia... e que tiveram uma atuação aqui nos cursos... de modo que não estranhem... a:: a a a orientação pouco peculiar que eu vou dar a essa palestra... 
A introdução é uma parte importante numa conferência já que é nela que se estabelece o primeiro contato com o auditório: é o momento em que se cria uma expectativa e se procura a adesão dos ouvintes. $\mathrm{O}$ ato de informar o auditório sobre o que se discorrerá e, sobretudo, como se fará isso, dando a idéia do todo, tem um forte valor interativo, pois facilita a compreensão do auditório acarretando conseqüentemente seu envolvimento. Sabedor disso, o locutor procura situar o auditório em relação ao que se discorrerá, indicando a singularidade da abordagem a ser feita, justificando-a e informando sobre as partes a serem desenvolvidas. Isso é feito num discurso organizado estruturalmente de forma bastante coesa e coerente tanto do ponto de vista da organização hierárquica dos itens que constituem o tópico quanto da seqüenciação desses itens. Assim, no plano vertical, a relação de subordinação dos subtópicos (desvio temático, justificativas, anúncio das partes da palestra) ao tópico (abordagem do tema) cria um efeito de coerência temática e de expectativa de autenticidade já que a fala do locutor, situando-se num período e num espaço (a estética na Faculdade de Filosofia USP) vai ter, na verdade, um caráter testemunhal que legitima sua fala, pois as personagens e os eventos de que vai tratar fizeram parte de seu universo de experiência por ter vivido/convivido com os fatos e as pessoas direta ou indiretamente. $\mathrm{O}$ etos desse locutor, testemunha de uma época (fundadora e marcante para a história da instituição), legitima a voz do especialista (o conferencista). O aspecto interativo está presente também na linearidade textual na medida em que a seqüenciação entre os subtópicos se faz de forma bem demarcada de maneira a orientar o ouvinte no percurso discursivo do locutor.

Os segmentos em negrito e em itálico no texto apresentam delimitadores discursivos que, embora não sejam marcadores discursivos de natureza padrão, convencional, constituem unidades limítrofes por compartilharem com estes alguns traços discursivos comuns, como o de anunciar o que se vai fazer, introduzir tópico/subtópico, justificar, modalizar o ponto de vista do falante. A respeito dessas unidades limítrofes, que funcionam como delimitadores discursivos, os analistas da conversação Risso, Silva \& Urbano (1996: 50) afirmam:

Trata-se de um campo bastante heterogêneo, que abrange estratégias metadiscursivas variadas de organização do fluxo informacional perante o interlocutor, operadores argumentativos, indicações de um ponto de vista pessoal, sintetizadores, modalizadores discursivos (...)

Assim, além da presença de elementos típicos da fala como os marcadores prosódicos (pausas, alongamentos, alteamento de voz); da presença de marcadores lingüísticos verbais lexicalizados e não lexicalizados, e de processos de formulação próprios da fala como fragmentação frástica, hesitação, repetição, correção, temos unidades discursivas limítrofes que funcionam como marcadores e organizam o texto metadiscursivamente exercendo papel pragmático-interacional. São traços do escrito que emergem em gêneros discursivos de expressão falada pertencentes ao que se tem chamado de Elocução Formal, indiciando uma forte preocupação com o planejamento do texto como um todo. Como a introdução está toda ela voltada para esse planejamento do todo textual, caracteriza-se pelo seu alto teor metadiscursivo. 


\subsection{O desenvolvimento: fluxo informacional e inserções}

A organização tópica segue, no desenvolvimento, as mesmas estratégias da introdução: a preocupação em informar o ouvinte a respeito do que se vai tratar sumarizando, brevemente, o todo e, depois, desenvolvendo cada sub-parte, havendo uma coesão bastante cerrada tanto do ponto de vista hierárquico quanto seqüencial, com presença de marcadores discursivos de caráter limítrofe. Para não ser repetitivo e por uma questão de economia, limitar-me-ei a, apenas, apontar as relações tópico/subtópicos, para me deter num aspecto da sequienciação tópica que me chamou a atenção e diz respeito diretamente à questão do fluxo informacional: o mecanismo das inserções.

O desenvolvimento se desdobra em dois tópicos: T2 + T3

Tema do T2: "As manifestações estéticas no decênio de 30". Compreende três subtópicos:

Subtópico 1: As várias atividades estéticas exercidas na época (Licínio Cardoso, Sérgio Milliet, Luís Martins, Manuel Bandeira, Flávio de Carvalho, Warchavchick, Rino Levi) - linhas 33 a 94. Este subtópico tem como função contextualizar, introduzir o auditório no ambiente estético da época, daí a menção aos diferentes estetas.

Subtópico 2: As atividades estéticas na Faculdade de Filosofia: os cursos eram dados por três professores franceses. Este subtópico se desdobra, essencialmente, em três sequiências tópicas: a) atividades do professor Lévi-Strauss (linhas 140 - 250); b) atividades do prof. Jean Moguet (linhas 250 - 456); c) atividades do prof. Roger Bastide (linhas 456 - 596).

Subtópico 3: Relação desses professores franceses com Mário de Andrade, mostrando as diferenças, identidades e polêmicas estabelecidas (linhas 596 - 750).

Tema do T3: A estética de Mário de Andrade (Como já dissemos, não focalizaremos esta parte em nossa análise).

Essa distribuição tópica na linearidade discursiva em que cada parte se encontra bem costurada à anterior e à subsequente, tanto do ponto de vista temático quanto do ponto de vista lingüístico-discursivo, mostra o aspecto planejado (próprio do escrito) que geralmente um gênero de elocução formal costuma apresentar. No caso desta conferência, a par da preocupação com o planejamento que visa a um efeito de coerência, a organização tópica se vê várias vezes afetada por uma certa descontinuidade própria da dinamicidade da fala. Isto é, em alguns momentos há uma espécie de perturbação da seqüência linear do texto provocada pelo que os analistas têm chamado de inserções (Jubran, 1993). A inserção é a interpolação no tópico em desenvolvimento de segmentos de natureza e extensão variadas que funcionam como elementos de ruptura em determinado ponto da linearidade conversacional. 
Vejamos algumas dessas ocorrências no texto em análise:

82 receberam pelos jornais muitos

ataques que provocaram polêmicas... polêmicas em

que -- como... a maioria das polêmicas dessa au/

dessa época -- ...uma das figuras principais...foi

140 Lévi-Strauss...chegou ao Brasil com

vinte e sete anos ... era professor de Etnografia...

[...] e... amando a pintura...como em geral...todo pro/

todo francês de de de formação...intelectual...e... amando a música - como nós vemos pelos livros

que ele continua escrevendo e que muitos deles têm uma...uma:: (tem) títulos ou em subtítulos tirados da:: da:: da nomenclatura musical... como acontece com

Cru e Cozido -- ...((tosse)) a preocupação

de Lévi-Strauss pela pintura

154 [...] é uma série de entrevistas que ele fez à televisão francesa - não

me lembro exatamente a época -- ...onde...ele dá o seu testemunho

$159[\ldots]$ sobre a:: a dissolução da pintura como ele via...

ali se transformando de pintura cubista em pintura

abstrata...((pigarreou)) - provavelmente é uma

curiosidade bibliográfica - e muita gente nunca

soube...que...no Brasil...ah Lévi-Strauss escreveu

dois...ensaios ou dois pequenos artigos...

255 (Moguet) vai rejeitar o impressionismo... -- mas vamos por

partes -- ... se Lévi-Strauss se transformou num dos

maiores nomes... da:: ah:: filosofia e da antropologia

259 [...] Jean (Moguet) é... - a não ser para nós

que tivemos a sorte a eNORme realmente

ventura de ser seus alunos - ele é um desconhecido...

273 [...] no Brasil ele deixou dois artigos... ou

três ou quatro... - eu não me lembro... estou me

lembrando agora de dois -- ... há um artigo muito importante

277 ele era um escritor Extraordinário...e se

nós não soubéssemos...qual era o autor desses artigos

podíamos sem dúvida a das boas coisas de um homem

como Merleau Ponty por exemplo... - ele tinha

(VIII)

algumas peculiarida::des ((tosse)) por exemplo quando

nós... nos (apresentávamos aos) exames... de

seleção...ele exigia dos alunos NÃO que tivessem

lido os livros de Filosofia... ele nunca perguntava

se nós tínhamos lido Matéria e Memória... se nós

tínhamos lido A Crítica do Juízo...ele perguntava

quais os romances que leu... porque ele achava que 
um aluno que se apresentava para um primeiro exame

de filosofia...não podia ter li/ ter compreendido

ainda a Filosofia mas tinha obrigação... de ter lido a

literatura...então ele perguntava já leu Crime e

Castigo... já leu o Père Goriot... lá/ já leu...

O Vermelho e o Preto... e ficava indignado

quando a gente queria tentava dizer que tinha lido

Descartes ele dizia o que que vai fazer com Descartes

se não leu a literatura --... para ele ( ) os os os

artigos que nos interessam são...dois artigos...um que

ele escreveu em mil novecentos e trinta e oito

Essas ocorrências têm "características de frases parentéticas e a sua brevidade não provoca propriamente uma cisão do tópico em porções nitidamente separáveis" (Jubran, 1993:64); dão-se numa estrutura $\mathrm{A}[\mathrm{X}] \mathrm{A}$, com uma breve interrupção e retomada imediata. De comum, nota-se que os segmentos inseridos são, em geral, introduzidos por elementos lexicalizados que funcionam como marcadores discursivos (como, provavelmente, mas, a não ser)ou por embreantes que indiciam a subjetividade do locutor. Essas suspensões temporárias (ou simples desvios) do tópico em andamento têm importantes funções pragmático-interacionais:

- $\quad$ em I, a inserção tem por objetivo fornecer uma explicação acessória a um público de outra época;

- $\quad$ em II, a inserção é um enunciado de caráter generalizante que pressupõe um lugar comum partilhado com o ouvinte; em IIa, a inserção desloca, estrategicamente, a narrativa do passado para o presente, favorecendo a interação na medida em que se cria uma conivência entre conferencista e auditório, pela convergência temporal e conhecimento partilhado;

- $\quad$ em III, VI e VII, emerge o eu do locutor, que busca no processo de enunciação a reconstrução discursiva do passado pela via da memória (que falha) e da avaliação/reminiscência positiva e afetiva de uma época;

- $\quad$ em IV, tem-se uma inserção de caráter comentador em que o modalizador (provavelmente) atenua a avaliação que se faz;

- $\quad$ em V, introduz-se um comentário de caráter metaformulativo na medida em que tendo o locutor avançado no desenvolvimento do assunto, se detém para retomar o percurso previamente traçado;

- $\quad$ em VIII, é a memória plena ( e não a que falha como em II e VII) que traz à tona episódios do passado que vivificam a exposição pelo que têm de testemunho pessoal; é interessante notar que aqui nesse relato, a linguagem acadêmica, formal que trata seus interlocutores de "senhores", como nesse trecho,

406: “-- há um trecho de Van Gogh... que eu vou ler para os senhores porque ele é muito típico das meditações de (Moguet)..." 
se descontrai, permitindo o uso do informal "a gente" (linha 294), que imprime ao depoimento um tom mais coloquial.

Como essas inserções não acarretam um forte rompimento do quadro de relevância temática, não afetam a coesão da unidade discursiva. São típicas da língua falada que, numa estratégia de planejamento diferente da escrita, deixa a nu o seu rascunho. Não rompendo com a coesão do texto, apenas desaceleram o fluxo informacional (Souza-e-Silva \& Koch, 1996) e são importantes do ponto de vista pragmático-interacional, pois propiciam o envolvimento do locutor com o ouvinte, de ambos com o tema, facilitando a intercompreensão.

Ao lado dessas inserções, marcas enunciativas com forte função interacional, como já disse, um aspecto importante a se observar ainda, e que "aproxima a elocução formal da composição do texto escrito" (Brait, 1998) ${ }^{2}$, é a presença da citação textual em que a locutora, em vários momentos da sua exposição, introduz polifonicamente outras vozes. A estratégia da citação se faz de forma pouco variável, reproduzindo-se, de modo geral, textualmente a fonte (o que caracteriza o texto escrito) mas, às vezes, determinada pelas condições da oralidade, a citação vem entrecortada pelo comentário do locutor, que, para delimitar a fronteira entre a voz citada e a voz citante, recorre aos verbos de dizer (diz ele. lembra ele...) ou a expressões de valor autonímico (para ele, segundo X...) nas paráfrases. (Exs: 1.: 326; 393 a 400; 406 a 443).

\section{CONCLUSÃO}

Como evento interacional institucional com objetivo definido e situação de contextos restritivos e assimétricos em que os papéis são fixados previamente e a posse do turno é convencionalmente atribuída a um locutor (discurso monogerado em situação formal), a conferência, como gênero discursivo híbrido, trabalha ao mesmo tempo com estratégias do escrito e do falado, o que nos leva a caracterizá-la como um gênero falado de estilo escrito.

\section{$\overline{\text { BIBLIOGRAFIA }}$}

BAKHTIN, M. (Voloshinov, 1929), Marxismo e filosofia da linguagem, trad. M. Lahud e Y.F. Vieira, São Paulo, SP, Hucitec, 1979.

. "Os gêneros do discurso", em Estética da criação verbal, trad. M.E. Galvão Gomes Pereira, São Paulo, SP, Martins Fontes, 1992, 277-326.

BRAIT, B., (1998), "Elocução formal: o dinamismo da oralidade e as formalidades da escrita", em D. Preti, (Org.), Estudos de língua falada. Variações e confrontos, São Paulo, SP, Humanitas - FFLCH-USP, 87-108.

${ }^{2}$ A observação de Brait (1998) diz respeito à análise de outro texto de elocução formal, o inquérito no. 153, e revela, pelas semelhanças de aspectos aí apontados, certas regularidades que caracterizam o gênero. 
BRAIT, B. (2002), "Interação, gênero e estilo", em D. Preti (org), Interação na fala e na escrita, São Paulo, SP, Humanitas - FFLCH/USP, 125-157.

CASTILHO, A.T. \& PRETI, D. (Orgs.), (1986), A linguagem falada culta na cidade de São Paulo, São Paulo, SP, T.A. Queiroz, Vol. I .

CHAFE, W.L. (1985). "Diferenças lingüísticas produzidas pelas diferenças entre fala e escrita" em D. R. Olson, N. Torrance, \& A. Hilyard, Literacy, Language and Learning: the nature and consequences of reading and writing, Cambridge, Cambridge University Press, trad. Marcos Bagno, 1992 (versão digitada).

JUBRAN, C.C.A.S. (1993), "Inserção: um fenômeno de descontinuidade na organização tópica", em A.T. Castilho, (Org.), Gramática do Português falado. As abordagens. Campinas, Editora da UNICAMP; São Paulo, FAPESP, 61-74.

JUBRAN, C.C. et alii (1996) "Organização tópica da conversação" em R. Ilari, (Org.) Gramática do Português falado. Níveis de análise lingüistica, Vol. II, Campinas, Editora da UNICAMP, $3^{\mathrm{a}}$. ed, 357-439.

KOCH, P. \& OESTERREICHER, W. (2002) "Langage parlé et langage écrit" (Gesprochene Sprache und geschriebene Sprache), em Günter Holtus et alii (éditores), Lexikon der Romanistischenn Linguistik $(L R L)$, Volume I, 2. Tübingen: Max Niemeyer Verlag.

MARCUSCHI, L.A. (2000). Da fala para a escrita. Atividades de retextualização, São Paulo, SP, Cortez Editora. (1993). "O tratamento da oralidade no ensino de língua", Programa de Pós-graduação em Letras e Lingüística, Recife, PE, Universidade Federal de Pernambuco (versão digitada). . (1988) “Coesão e coerência na conversação (Organização tópica)”. (Versão digitada).

RISSO, M. \& SILVA, G. \& URBANO, H. (1996). "Marcadores discursivos: traços definidores”, em I. Koch, (Org.), Gramática do português falado. Desenvolvimentos. Vol. VI, Campinas, SP, Editora da UNICAMP - FAPESP, 21-94.

SOUZA-e-SILVA, M.C. \& KOCH, I.V. (1996). "Estratégias de desaceleração do texto falado", em M. Kato, (Org.), Gramática do português falado. Convergências, Vol. V, Campinas, SP, Editora da UNICAMP - FAPESP, 327-338. 